\title{
Da montagem ao collage: found footage, voz-over e filme-ensaio
}

\section{From montage to collage: found footage, voice-over and essay-film}

Rafael de Almeida ${ }^{1}$

Resumo: Objetiva-se investigar, à luz de Seams (Karim Aïnouz, 1993), como a voz-over, o found footage e o filme-ensaio são colocados em relação, bem como se comportam enquanto práticas criativas autônomas, em obras que reutilizem imagens de arquivo. Partimos da hipótese de que a aproximação entre esses elementos se dá, sobretudo, por meio do procedimento de montagem, encontrando-se frequentemente conectado com a noção de collage. Pretende-se analisar os procedimentos de montagem do filme, para por fim sinalizar que o collage é o responsável não apenas por colocar em relação criativa a voz-over, o found footage e o filme-ensaio, mas por garantir que esses elementos potencializem seus papéis narrativos diante da construção textual discursiva e crítica, sobre o machismo brasileiro, pretendida pelo curta-metragem.

Palavras-chave: found footage; voz-over metacrítica; filme-ensaio; collage; Seams (filme).

Abstract: The objective is to investigate, in the light of Seams (Karim Aïnouz, 1993), how voice-over, found footage and film-essay are put in relation as well as behave as autonomous creative practices in works that reuse archival footage. Our hypothesis is that the approximation between these elements occurs mainly through the editing procedure, being often connected with the notion of collage. We intend to analyze the editing procedures of the film, to finally signal that the collage is responsible not only for putting in a creative relation the voice-over, the found footage and the film-essay, but for ensuring that these elements enhance

1 Universidade Estadual de Goiás (UEG). Anápolis, GO, Brasil.

https://orcid.org/0000-0002-7088-234X. E-mail: rafaeldealmeidaborges@gmail.com 
their narrative roles before the discursive and critical textual construction, about Brazilian machismo, intended by the short film.

Keywords: found footage; metacritical voice-over; essay-film; collage; Seams (film). 


\section{Introdução}

A reflexão aqui proposta interessa-se pelo diálogo entre a voz-over, o found footage e o filme-ensaio como forma de ampliar a nossa compreensão do procedimento de montagem em obras que se valham parcialmente ou em sua totalidade de materiais de arquivo. À luz de Seams (Karim Aïnouz, 1993), objetiva-se investigar o papel operado pela montagem ao colocar esses três elementos em diálogo.

Seams é um filme-ensaio em curta-metragem que, a partir de uma perspectiva subjetiva, reflete sobre a problemática da opressão feminina no contexto brasileiro. Conduzida por uma voz over masculina e analítica, a narrativa mescla entrevistas, com sequências encenadas e uma ampla variedade de imagens de arquivo, fazendo uso da técnica de found footage. Sendo assim, enquanto o filme se propõe a realizar um retrato afetivo (e das afetividades) da avó do diretor e suas quatro irmãs, simultaneamente traz à tona uma reflexão que transcende o universo do sujeito enunciador e alcança o mundo social: o machismo na sociedade brasileira.

Por essa perspectiva, o problema de pesquisa a que nos dedicamos questiona, à luz de Seams, como a voz-over, o found footage e o filme-ensaio são colocados em relação, bem como se comportam enquanto práticas criativas autônomas, em obras que reutilizem imagens de arquivo.

Partimos da hipótese de que a aproximação entre esses elementos se dá, sobretudo, por meio do procedimento de montagem, encontrando-se frequentemente conectado com a noção de collage, "uma técnica criativa que é também um método crítico" (WEES, 1993, p. 52, tradução nossa). Por ser "regido pelos princípios de descentralização e dispersão, o collage 'está dominado por múltiplas posições de observação: cada fragmento é móvel e aberto à interação com uma multidão de contextos semânticos, simbólicos, estéticos etc." (ELENA, 2009, p. 217, tradução nossa). Por meio das práticas coincidentes da voz-over, do found footage e do filme-ensaio, as imagens de arquivo parecem assumir 
um caráter de fragmento que permite sua articulação por meio da montagem compreendida como collage.

Isso porque partimos da compreensão de que o collage pode ser percebido como um procedimento compositivo em que a montagem "transcende sua dimensão puramente técnica de justaposição de planos para alcançar uma dimensão estética que pressupõe uma vontade evidente de enfatizar a heterogeneidade dos materiais utilizados, de fazê-los entrar em conflito, de estabelecer entre eles uma relação dialética" (VAQUERO; LÓPEZ, 2009, p. 26, tradução nossa). Ou seja, embora reconheçamos que toda montagem pressuponha certa dimensão estética, em geral ela busca mais invisibilizar que realçar as conexões entre os planos. O collage, como veremos, irá na contramão disso.

Interessados em compreender os procedimentos de montagem em Seams a partir desses três elementos - a reflexão em torno da técnica de found footage; a discussão acerca da voz-over; e o estudo sobre a forma e as características do filme-ensaio - analisaremos a obra por meio de uma investigação formal e analítica de determinadas sequências do filme, precedida de uma decupagem. A partir disso, pretendemos verificar como a montagem, compreendida pela perspectiva do collage, põe tais elementos em relação e contribui para a construção discursiva do filme.

Pretendemos em um primeiro instante refletir sobre o collage enquanto um dos tipos de montagem para filmes de found footage. Logo em seguida, desejamos perceber o uso da voz-over como um procedimento de montagem, por meio da exploração do conceito de voz metacrítica. Com esse plano de fundo em vista, partiremos para uma compreensão de Seams enquanto filme-ensaio, construído por meio do comentário verbal e da montagem compreendida como collage.

\section{Do found footage ao collage}

Imagens de arquivo em preto e branco. Plano 1: homem saindo de uma mata. Plano 2: em plano americano, um homem de costas com uma 
espingarda e uma peixeira nas costas. Plano 3: o homem atira em um jacaré, que cai na água de um lago a sua frente.

Figura 1 - Frames do filme Seams
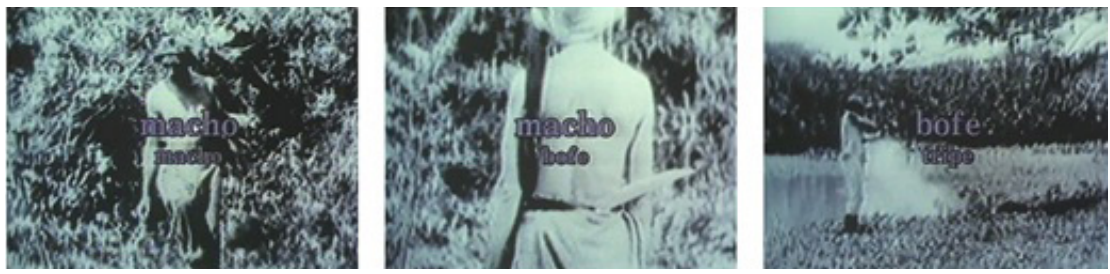

Fonte: Reprodução

Plano 4: homem posa para a câmera orgulhoso, agachado e segurando a arma com o jacaré morto diante de si. Plano 5: fotografia antiga profissional, que reúne sete homens, todos usam traje social e bigodes. Plano 6: dois homens cortam um tronco de árvore a machadadas.

Figura 2 - Frames do filme Seams
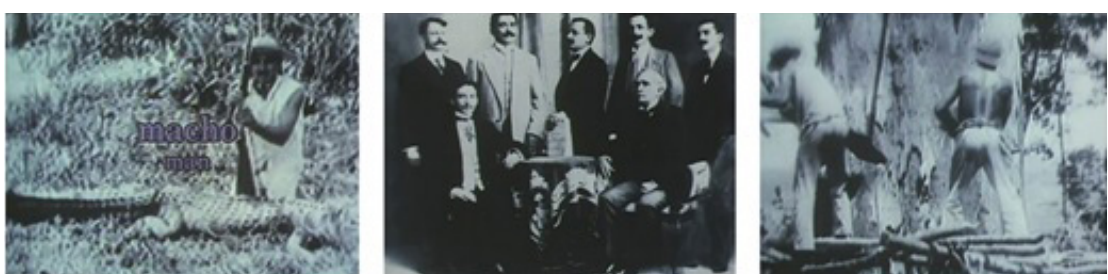

Fonte: Reprodução

Plano 7: homem quebra toco no chão com machado. Plano 8: panorâmica ágil da direita para esquerda de homem cavalgando e tentando laçar um bezerro, que corre a sua frente. Plano 9: três homens com armas a postos, um deles atira em um jacaré a sua frente. 
Figura 3 - Frames do filme Seams
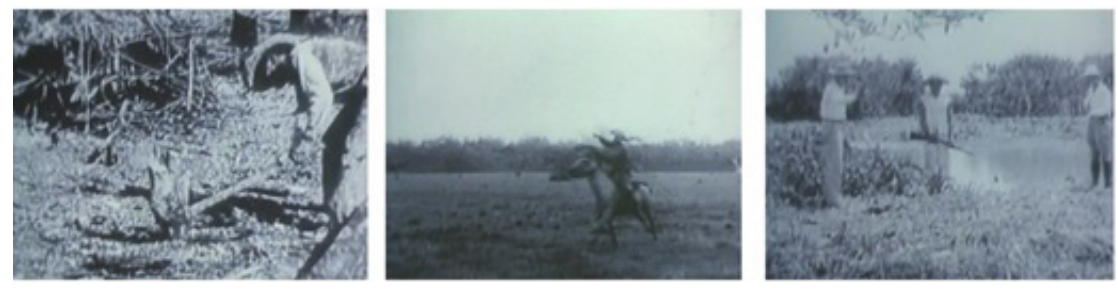

Fonte: Reprodução

Plano 10: jarros de cerâmica sobre uma mesa em fast motion, as flores tremulam. Plano 11: menino de uns dois anos se apoia em grades de ferro, se coloca de pé, se vira e aponta para a câmera. Plano 12: avião de pequeno porte taxiando.

Figura 4 - Frames do filme Seams
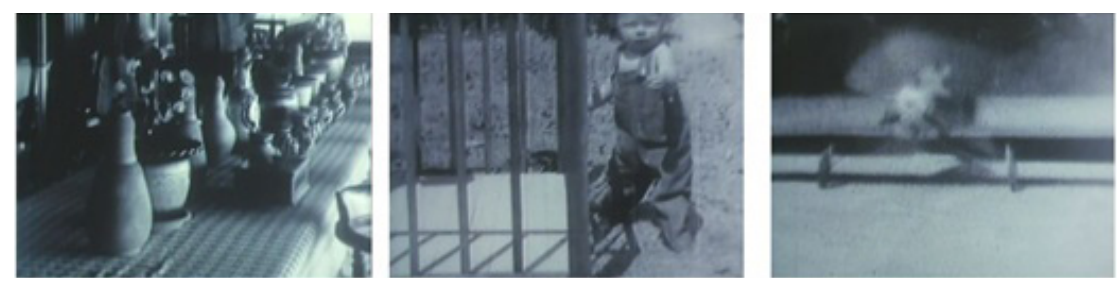

Fonte: Reprodução

Plano 13: garoto de uns 10 anos toma banho nu em uma torneira grande, no quintal. Plano 14: plano geral do avião decolando.

Figura 5 - Frames do filme Seams
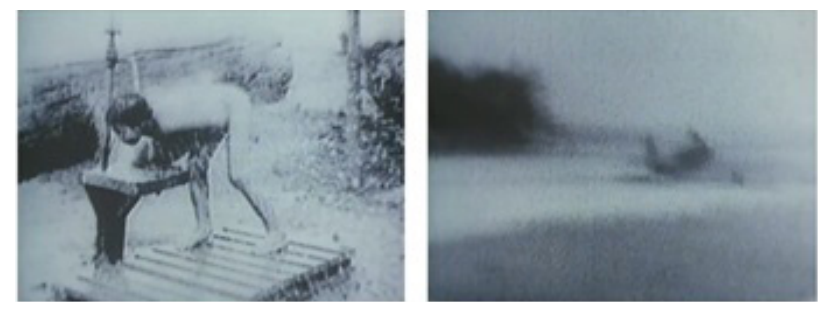

Fonte: Reprodução 
Seams faz amplo uso da técnica de found footage, aqui compreendida como procedimento que garante aos realizadores valerem-se da "mídia de massa com seu infinito suprimento de imagens esperando para serem arrancadas de seu contexto e reinseridas em filmes de collage, onde serão reconhecidas como fragmentos que ainda carregam as marcas de sua realidade midiática" (WEES, 1993, p. 46, tradução nossa). Nesse exercício de reapropriação, as imagens roubadas - aquelas que foram extraídas de seu lugar de origem -, apesar de não abandonarem por completo os contextos semânticos em que foram geradas, permitem-se empenhar outros papéis e geralmente ganham novos sentidos. Ou seja, de forma sintética, o found footage é o nome da técnica cinematográfica que se vale de materiais alheios, produzidos originalmente com outras finalidades.

William Wees (1993) propõe uma distinção entre três tipos de montagem found footage: compilação, collage e apropriação. Com isso, o autor sugere que as diferentes metodologias de usar a técnica de found footage se relacionam diretamente com distintos paradigmas da prática artística. Embora a categorização proposta pelo autor corra o risco de ser reducionista, parece-nos um importante ponto de partida por indicar as metodologias predominantes na construção de filmes feitos parcialmente ou em sua totalidade com materiais de arquivo. A partir de Wees, compreendemos que:

1. com a metodologia de compilação, o found footage estaria em busca de materiais de arquivo com forte caráter factual, capazes de se associar à realidade e induzir uma leitura documentarizante ${ }^{2}$, como em filmes documentários convencionais, amparados por uma tendência estética realista.

2. com a metodologia de collage, o found footage manejaria os arquivos menos pelo seu caráter de documento, do que pelas possibilidades criativas instauradas pela sua compreensão enquanto imagem,

2 Para mais informações sobre os modos de leitura, sugerimos a leitura de "A questão do público: uma abordagem semiopragmática", de Roger Odin. 
levando a uma leitura estética, como nos filmes de vanguarda, apoiados por uma tendência estética moderna.

3. com a metodologia de apropriação, o found footage manusearia as imagens de arquivo por sua condição de simulacro, por sua capacidade de falsamente imitar a realidade, direcionando a uma leitura artística somente, como em clipes musicais, sustentados por uma tendência estética pós-moderna.

A partir do exposto, fica evidente que o collage diferencia-se da montagem tradicional por se tratar de uma das três metodologias específicas de montagem para filmes realizados por meio da técnica de found footage. Wees defende que a metodologia de collage "possui o melhor potencial para criticar, desafiar, e possivelmente subverter o poder das imagens produzidas, e distribuídas, por meio da mídia corporativa" (WEES, 1993, p. 33, tradução nossa).

Acredita-se que todas as imagens em preto e branco de Seams, rodadas na década de 1930, são parte da coleção Ford Motor Company, incorporada pelo Arquivo Nacional americano em 1963 (MACHADO; BLANK, 2015). A intenção original das imagens, portanto, era fazer publicidade de Henry Ford e sua companhia no contexto do frustrado projeto de desenvolvimento da cidade de Fordlândia, uma company town no Pará, às margens do Rio Tapajós, então construída para explorar a borracha das seringueiras.

Ora, se se tratam de imagens publicitárias vinculadas à imagem institucional de uma empresa multinacional, em seu contexto original a maioria dos planos descritos acima enaltecia a figura do homem enquanto desbravador. A imagem viril de um homem capaz de explorar percursos inóspitos dentro das matas, lidar com animais ferozes e proteger-se deles, extrair recursos naturais das árvores, manejar armas de fogo com segurança e domesticar animais do campo. No entanto, Karim parece fazer uso da metodologia de collage do found footage, o que subverte os sentidos planteados originalmente e promove uma postura crítica e analítica em relação às imagens e seus usos. 
Ainda que desconsideremos o primordial papel operado pela voz-over nesse momento; é perceptível que ao aglutinar em uma montagem dinâmica, com planos curtos e cortes secos, signos visuais que remetam à violência naturalizada empreendida por uma série de homens, o collage empreende uma crítica ao machismo brasileiro. Isso se reafirma quando o contraste é gerado com os planos 11 e 13, em que meninos - lidos como "projetos de homens" - tentam se colocar de pé ou cuidar de si com liberdade em um ambiente que os oprime. A metodologia do collage no found footage reafima o caráter da montagem enquanto operação violenta, utilizando-se disso em seu próprio favor.

Partimos do pressuposto de que a essência do cinema tem suas bases fincadas na fragmentação e heterogeneidade. A montagem é, portanto, ferramenta primordial para organizar a descontinuidade da qual partem as narrativas cinematográficas. No entanto, "precisamente a tradição da montagem consistiu em disfarçar a violência de sua própria operação, para oferecer uma aparência sem fissuras de continuidade (...)". A montagem aos poucos se tornou invisível. "Assim se desenvolveram os códigos da montagem tradicional que funcionam em um sentido oposto ao collage: podemos caracterizá-los nesse sentido como uma intenção de dissimular o contorno e ocultar a disparidade de elementos" (WEINRICHTER, 2009, p. 54, tradução nossa). Ao dissimular o contorno dos planos, a violência da operação de montagem é aparentemente reduzida em favor de uma recepção acrítica e submissa por parte do espectador. O collage assumirá o sentido oposto desse movimento.

Portanto, os filmes de collage desmontam e/ou remontam seus materiais de arquivo, de forma a dificultar uma recepção das imagens tanto enquanto provas da realidade (como previsto pelo filme de compilação ${ }^{3}$ ) bem como enquanto imagens que não possuem qualquer relação com

3 Na esteira de Wees (1993), compreendemos o filme de compilação enquanto um produto realizado por meio da técnica de found footage, com montagem por meio da metodologia de compilação. Ou seja, o que interessa ao filme de compilação é a pesquisa e o ordenamento de materiais de arquivo com eminente valor documental. Em geral, documentários históricos que manejem uma quantidade expressiva de materiais de arquivo enquanto provas discursivas poderiam ser considerados filmes de compilação. 
realidade (como previsto pelo filme de apropriação ${ }^{4}$ ). Nos filmes-ensaio que se valem do collage "existe um questionamento, ou ceticismo, constante acerca do significado das imagens de arquivo" (ARTHUR, 2008, p. 171), em geral materializado por uma voz-over analítica e crítica.

\section{Voz-over metacrítica e collage}

Imagens de arquivo em preto e branco. Plano 1: um jovem casal percorre uma estrada em um carro conversível. Plano 2: em um plano mais próximo, eles se entreolham sorridentes, enquanto o homem dirige. Plano 3: as ondas do mar tocam os pés de uma menina deitada de bruços na beira do mar, recostada sobre os cotovelos e olhando para a câmera.

Figura 6 - Frames do filme Seams
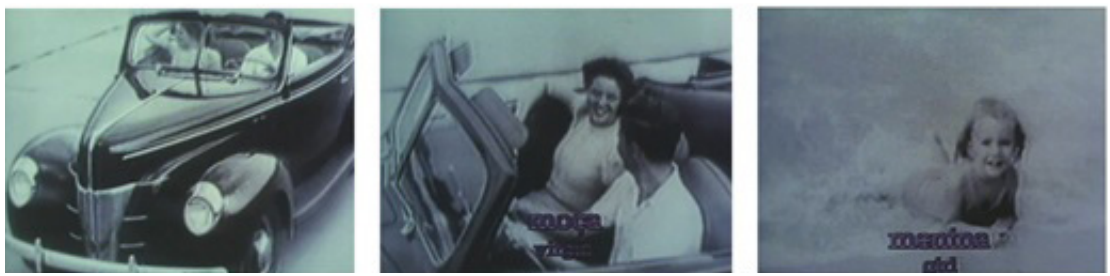

Fonte: Reprodução

Plano 4: em uma lenta panorâmica da esquerda para a direita, a câmera revela mulheres de várias idades sentadas em uma arquibancada. Uma delas segura um guarda-chuva. Plano 5: um homem manipula o que parece ser uma câmera antiga, em plano médio. Plano 6: um grupo de mulheres sorridentes fita a câmera.

4 Também a partir de Wees (1993), percebemos o filme de apropriação enquanto um produto realizado por meio da técnica de found footage, com montagem por meio da metodologia de apropriação. Isto é, ao filme de apropriação o que importa é o caráter de artifício da imagem encontrada e rearranjada pela montagem. Normalmente, videoclipes musicais que utilizem uma grande quantidade de materiais de arquivo, enquanto figuras sensoriais desconectadas de seu contexto semântico original, poderiam ser compreendidos enquanto filmes de apropriação. 
Figura 7 - Frames do filme Seams
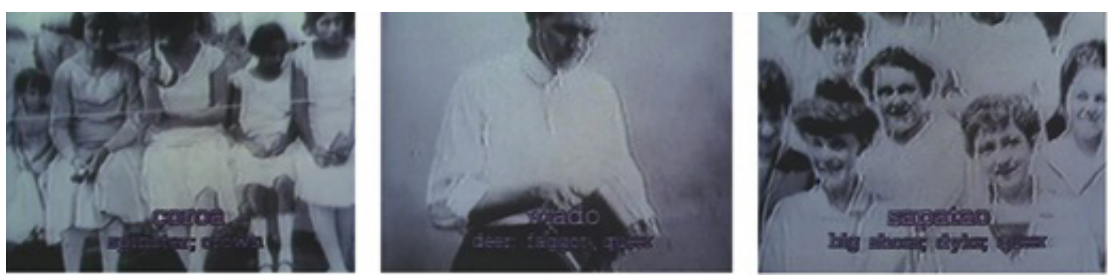

Fonte: Reprodução

Plano 7: três mulheres de braços dados caminham, exibindo seus vestidos e chapéus com penas. Plano 8: em um pequeno grupo, mulheres se cumprimentam apertando as mãos. Plano 9: duas mulheres caminham na beira da piscina até que ambas jogam um pedaço de pão na água.

Figura 8 - Frames do filme Seams
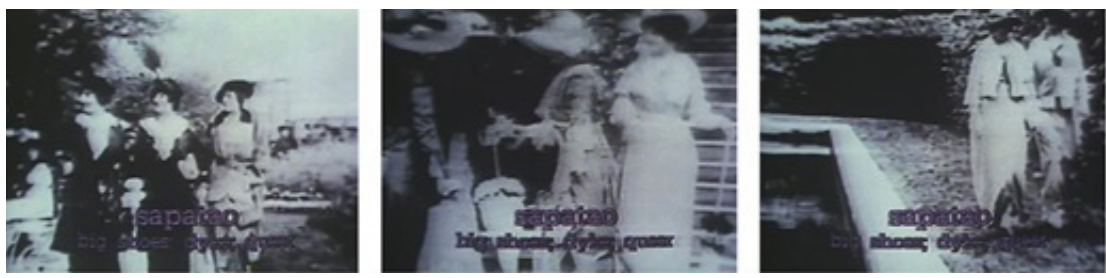

Fonte: Reprodução

Plano 10: duas mulheres dançam juntas em um salão, segurando as mãos. Plano 11: uma menina sorri, levando a mão até a boca e a retirando em seguida. Plano 12: duas adolescentes, uma ao lado da outra, sorriem e seguram flores. 
Figura 9 - Frames do filme Seams
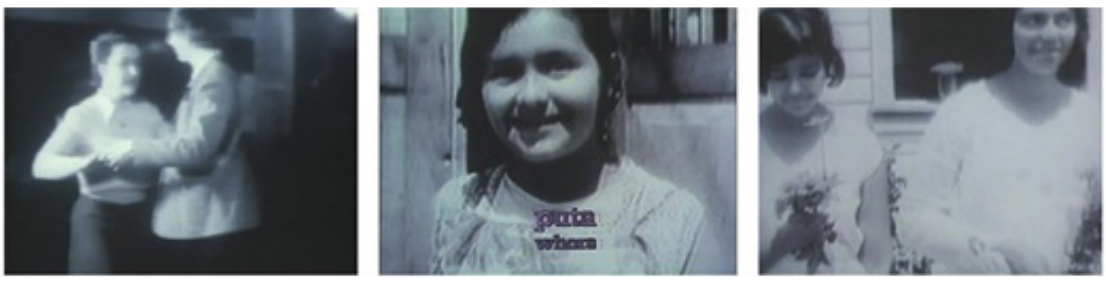

Fonte: Reprodução

Plano 13: dois homens em cima de um palanque. Plano 14: em plano geral, vemos uma aula de balé para meninas, enquanto uma freira as monitora cruzando o quadro. Plano 15: alguns meninos divertem-se sentados numa escada, enquanto um deles dá um beijo no rosto do amigo.

Figura 10 - Frames do filme Seams
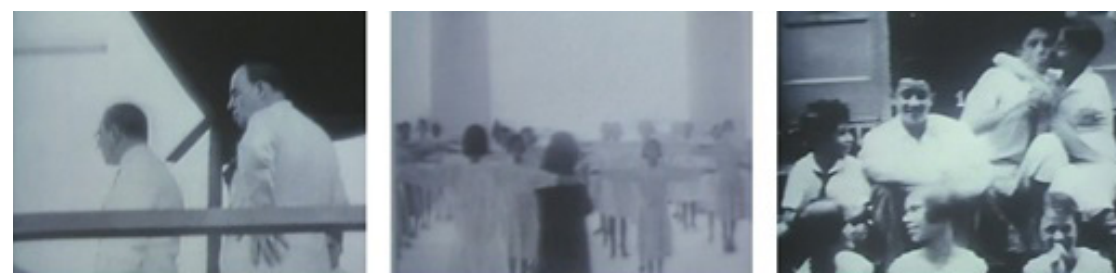

Fonte: Reprodução

Em Seams os arquivos são usados menos pelo seu caráter de evidência histórica do que pela capacidade de gerar espaços reflexivos e de envolvimento crítico na relação criada com o comentário verbal. Os arquivos não abandonam completamente seus sentidos originais, mas também obtêm outros no novo arranjo. Enquanto vemos cada um dos planos da sequência descrita acima, ouvimos, em inglês, a seguinte narração em voz-over:

Em português, moça significa virgin. Menina significa girl. Mulher significa woman. Coroa significa spinster, mas também significa crown. Veado significa deer, que também significa faggot, que significa queer. Sapatão 
significa big shoes, mas também significa dyker, que significa queer. No nordeste a palavra lésbica quase nunca é usada. Puta significa whore. É a pior coisa de que alguém pode chamar uma mulher se quiser insultá-la. Se alguém quiser insultar um homem o chama de veado, que significa faggot. Toda menina teme ser chamada de puta. Eu temi a palavra veado desde que eu era pequeno. (Seams, Karim Aïnouz, 1993, tradução nossa)

Sendo assim, a voz-over - compreendida enquanto uma voz extradiegética pertencente ao sujeito narrador - se permite atuar de forma irônica, que também significa sarcástica, que significa crítica. A narração propõe um jogo entre o explícito e o implícito, de forma que aquilo que se diz não é necessariamente o que se deseja significar por completo. Essa capacidade discursiva é fruto de uma cuidadosa investigação dos sentidos impregnados tanto pelos signos visuais, que constroem aquilo que socialmente compreende-se por masculinidades e feminilidades aceitáveis nos materiais de arquivo, quanto pelos vocábulos que têm seus múltiplos significados dissecadas pelo narrador, sobrepostos às imagens com a intenção de gerar colisões que subvertam seus sentidos originais.

Portanto, por um lado temos que a técnica de found footage, ao incorporar material filmado previamente em novas obras, "investiga criticamente a história por trás da imagem, incorporada discursivamente em sua história de produção, circulação e consumo" (ZRYD, 2003, p. 42, tradução nossa). Ou seja, para Zryd é uma forma meta-histórica que critica os padrões narrativos por trás da história. Por outro lado, o uso da voz-over garante ao realizador a possibilidade de "comentar a partir de um distanciamento crítico, analisar e interpretar os recursos visuais" (RASCAROLI, 2009, p. 52, tradução nossa). Dessa maneira, a voz-over comporta-se como canal privilegiado para que um (re)exame preciso das imagens de arquivo empregadas seja realizado.

O plano 15 da sequência descrita é acompanhada da narração: "Eu temi a palavra veado desde que eu era pequeno". Considerando a fonte das imagens, a intenção original do plano 15 também era fazer publicidade de Henry Ford e sua companhia. Ao retirar o plano de seu contexto original e reintegrá-lo em um novo contexto semântico, por meio da 
técnica de found footage, Karim nos impede de vincular tal imagem aos seus propósitos publicitários originais.

Descontextualizado, o plano assemelha-se a um registro doméstico, em que podemos imaginar um pai filmando seu filho cercado pelos amigos, sentados na escadaria da escola. O dispositivo da câmera impulsiona o beijo entre dois meninos: como um jogo, como algo que não pudesse ser feito, como algo que "prejudicasse" a imagem daquele que é beijado. Ao reciclar esse plano, Karim parece empreender, portanto, uma crítica à maneira como as imagens publicitárias materializam as demonstrações de afeto entre dois meninos. Found footage. Crítica.

Simultaneamente, ouvimos uma voz jovial masculina dizer: "Eu temi a palavra veado desde que eu era pequeno". A voz-over assemelha debruçar-se sobre a imagem que temos diante de nossos olhos para revê-la, reexaminá-la, reavaliá-la. A conclusão a que o realizador chega é compartilhada conosco por meio do comentário verbal. Desse exercício fica evidente ao sujeito enunciador que não caberia qualquer demonstração de afeto entre dois meninos, a não ser que ela estivesse coberta pela lógica do jogo e do improvável. Sobretudo se algum deles imaginasse sentir-se atraído sexualmente pelo mesmo sexo, como parece ser o caso do sujeito que narra o filme. Voz-over metacrítica. Crítica da crítica.

Nesse contexto, a performance da crítica de uma crítica - comentário verbal da voz-over que examina os arquivos visuais do found footage, que depreciam os padrões discursivos dos mass media - garante a concepção da voz-over metacrítica (RASCAROLI, 2009). "Essa distância crítica frequentemente se assemelha ao posicionamento do cineasta no texto fílmico, que se afasta de trás da câmera, de sua função criativa, e se torna um metacrítico - das imagens, da sociedade que as produz, de seu próprio texto e de seu papel nisso" (RASCAROLI, 2009, p. 52, tradução nossa).

Dessa maneira, a voz-over metacrítica ensaística analisa "metodicamente sem método" (ADORNO, 2003, p. 30) as estruturas de sentido que sustentam o discurso visual das imagens de arquivo do filme de 
found footage. Isto é, pela perspectiva adorniana: por um lado, o ensaio deve desafiar a prioridade do método enquanto a essência do pensamento; por outro, o ensaio não deve abrir mão de procedimentos analíticos precisos e intrínsecos à leitura empreendida junto ao objeto analisado, permitindo-se ser fecundado por ele.

Sendo assim, os realizadores, "ao sobrepor um comentário, distanciam-se das imagens e as examinam, quase 'encontrando' e apresentando-as de novo, como objetos pré-existentes” (RASCAROLI, 2009, p. 52, tradução nossa). Logo, a voz-over metacrítica apresenta-se a nós enquanto um mecanismo de montagem essencialmente. Mecanismo capaz de investigar as imagens por meio de procedimentos peculiares que, embora não se pautem por um método específico, se valem de uma experiência singular e analítica dos cineastas com as próprias imagens. As quais orientam a maneira como o pensamento crítico se comporta e se materializa por meio da voz.

\section{Seams: collage e filme-ensaio}

Imagens de arquivo em preto e branco. Plano 1: câmera subjetiva de um teleférico que se aproxima da estação. Plano 2: câmera subjetiva de um helicóptero, em plano zenital, de um homem que se segura em sua escada enquanto a aeronave voa. Plano 3: uma menina dá cambalhota estrelinha.

Figura 11 - Frames do filme Seams
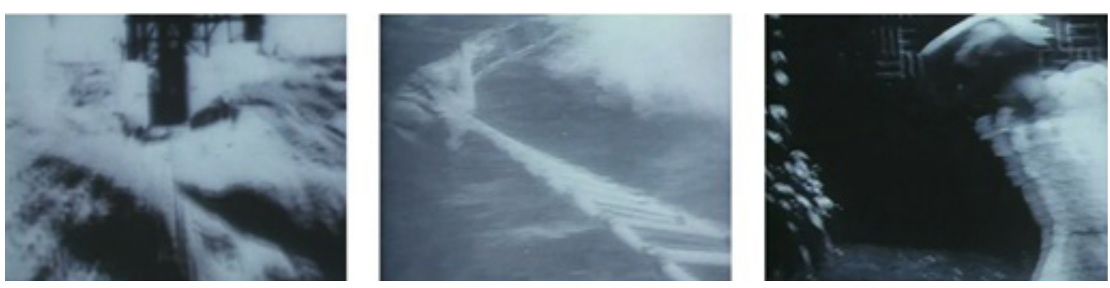

Fonte: Reprodução 
Plano 4: uma menina dá cambalhota estrelinha (repetição do plano 3). Plano 5: mulheres, de longos vestidos brancos e chapéus, correndo entre arbustos em direção à câmera. Plano 6: as mesmas mulheres pulam uma cerca e correm.

Figura 12 - Frames do filme Seams
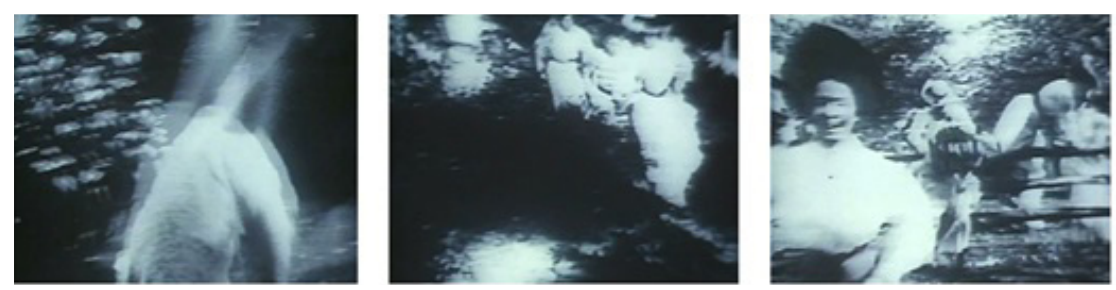

Fonte: Reprodução

Plano 7: crianças de uns 10 anos "brincam" em uma escada; um dos meninos levanta a saia de uma garota que tenta impedir e corre envergonhada em seguida; enquanto corre, ela leva um tapa na bunda de outro garoto. Plano 8: câmera subjetiva de um trem em movimento registra o caminho à sua frente. Plano 9: outro plano de câmera subjetiva de um trem em movimento que registra o caminho à sua frente.

Figura 13 - Frames do filme Seams
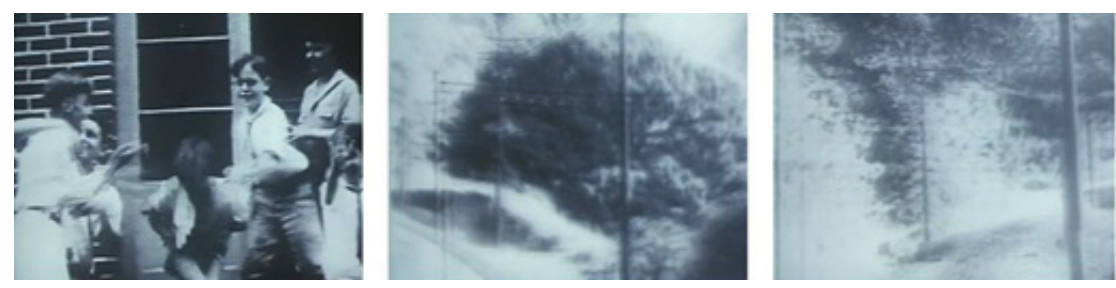

Fonte: Reprodução

Plano 10: menino de uns 3 anos, vestido como um príncipe com capa, manda um beijo para alguém que está fora de quadro; a ação se repete mais uma vez. Plano 11: dois homens bailam dança de salão juntos. Plano 12: explosão. 
Figura 14 - Frames do filme Seams
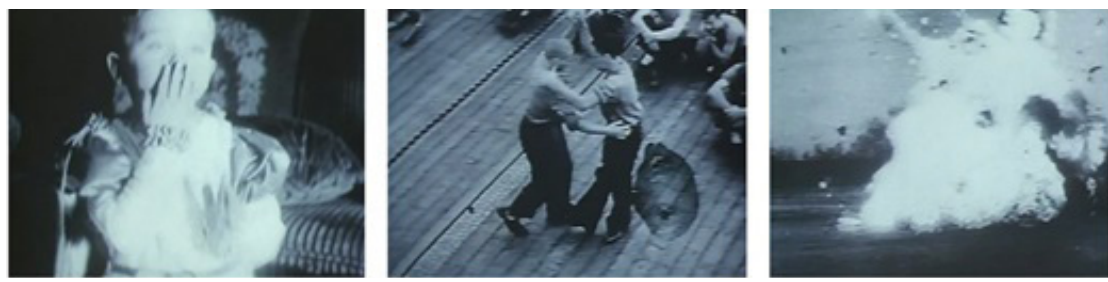

Fonte: Reprodução

Enquanto vemos os planos descritos acima, ouvimos:

Meu pesadelo: Zélia olha para mim e pergunta: "Você já tem 26 anos. Você não tem uma namorada?". Primeiro eu me inclino para a frente, olho para ela e digo: "Eu não consigo te ouvir". Quando ela pergunta pela segunda vez, eu respondo: "Não, não tenho. Não exatamente!". Eu também digo: "A vida é tão complicada". (Seams, Karim Aïnouz, 1993, tradução nossa).

Enquanto filme-ensaio, Seams ocupa o "espaço compreendido entre a elucubração subjetiva e a história social” (ARTHUR, 2008, p. 171, tradução nossa). O curta-metragem apresenta uma reflexão crítica e pessoal sobre um conjunto de questões que giram em torno do machismo na sociedade brasileira. Essa reflexão não se propõe "anônima ou coletiva”, mas como proveniente de um discurso autoral, materializado na voz-over metacrítica do sujeito narrador, que "aborda a questão do assunto não para apresentar um ostensivo relatório factual (o campo do documentário tradicional), mas para oferecer uma reflexão abertamente pessoal, profunda e instigante" (RASCAROLI, 2009, p. 33, tradução nossa). Nessa perspectiva, enquanto filme-ensaio construído por meio do collage, "o found footage desempenhou um papel decisivo em seu desenvolvimento, uma vez que proporcionou uma plataforma visual com a qual estabelecer conexões discursivas entre eventos que, em princípio, parecem díspares" (ARTHUR, 2008, p. 171, tradução nossa).

Karim parte de seu universo pessoal e da experiência subjetiva das tias-avós para fazer um retrato delas e de suas relações afetivas, marcadas 
pelo servilismo e pelo abandono dos homens que passaram por suas vidas. Embora tenha crescido rodeado por mulheres, o ambiente em que viveu foi marcado pelo machismo e pela opressão. Em um ambiente com tais características, não há espaço para outros tipos de masculinidade, que não a do homem que naturalmente cresce como "macho".

A metodologia do collage proveniente do found footage deixa isso evidente, ao contrastar elementos desiguais. Não há espaço para meninos como o do plano 10 da sequência descrita: que sejam príncipes, delicados e afetuosos, características destinadas somente às meninas. Muito menos para homens que dancem juntos, envolvendo com os braços uns a cintura dos outros, como no plano 11. Parece haver espaço somente para aqueles meninos que, desde a infância, lidem com o sexo oposto enquanto um corpo submisso, ainda que pela lógica da "brincadeira", como vimos no plano 7, em que a menina é constrangida. Para sobreviver em um ambiente como esse, só resta ao homem gay a negação da própria afetividade. E os homens dançam, enquanto o narrador nega: “Não, não tenho [namorada]. Não exatamente!". Mas o desejo talvez seja de explodir (a si próprio ou a esse universo), como representado pelo plano 12 .

Ao alcançar a estética ensaística do cinema, por meio do collage e da voz-over, Seams opera um trânsito reflexivo entre a homossexualidade declarada do realizador, em relação ao seu universo afetivo familiar, e o mundo social, onde há possibilidade de identificação e diálogo com espectadores igualmente oprimidos, em um largo espectro. Por meio do collage as imagens de Fordlândia são libertas "da lógica da propaganda e do capitalismo industrial" e "apresentadas a partir de uma perspectiva íntima que nada tem a ver com seu contexto de produção e, dessa forma, ganham uma dimensão poética e política" (MACHADO; BLANK, 2015 , p. 89). Por meio da voz-over a reflexão crítica ganha corpo por meio da possibilidade de voltar a ver e a examinar as imagens empregadas, bem como das colisões entre a banda sonora e imagética, que não dissimulam os contornos entre esses sons e imagens. 
É tentador citar a utilização de found footage e collage como endêmica para o ensaio, dado o grande número de filmes que contam com justaposições de imagens de arquivo e comentários verbais no tempo presente. No entanto, se ensaios não são invariavelmente heterogêneos em materiais, suas relações segmentares e de som-imagem tendem a implicar colisão ou crítica dialética. (ARTHUR, 2003, p. 59, tradução nossa)

A crítica discursiva do filme-ensaio de collage é amparada pela contraposição e contradição tanto dos materiais heterogêneos utilizados quanto da disjunção imagético-sonora reforçada pelo comentário em voz-over. Ao tratar da relação do collage com o filme-ensaio, Vaquero e López apontam que nesse contexto as imagens são tratadas pelo seu caráter residual, a partir do qual "é possível encontrar rastros dos usos que se deram no passado, postos em evidência e questionados a partir do presente". A intenção do collage, portanto, "é remarcar as bordas, mostrar de onde podem proceder as imagens, assim como surpreender o espectador com novas posições que aportem sentidos inéditos, relativizando assim a função e posição da imagem na sociedade atual (frente ao taxativo do discurso dominante)" (VAQUERO; LÓPEZ, 2009, p. 29). Se o collage no filme-ensaio permite essa reciclagem das imagens de found footage do passado, o comentário em voz-over permite essencialmente a recontextualização e crítica dessas imagens no tempo presente.

\section{Considerações finais}

Pelo caminho delineado até aqui pensamos ter evidenciado que a aproximação entre a voz-over, o found footage e o filme-ensaio se dá, sobretudo, por meio do procedimento de montagem compreendido como collage, em obras que reciclem imagens de arquivo. Além disso, entendemos que, enquanto práticas criativas autônomas: 1) o collage pode ser compreendido enquanto metodologia de montagem da técnica de found footage; 2) a voz-over metacrítica performa uma crítica da crítica ao reexaminar as imagens de arquivo reutilizadas; 3 ) o filme-ensaio de collage apoia sua reflexão crítica simultaneamente no contraste das 
imagens de found footage coletadas e na divisão entre som-imagem, reforçada pela presença da narração.

Sendo assim, o collage é o responsável não apenas por colocar em relação criativa a voz-over, o found footage e o filme-ensaio, mas por garantir que esses elementos potencializem seus papéis narrativos diante da construção textual discursiva e crítica pretendida pela obra, ao contrastar imagens de arquivos em sua heterogeneidade. Imagens tratadas pelo filme-ensaio pela perspectiva de uma "estética do fragmento" (ALMEIDA, 2017), que as percebe tão somente como imagens residuais de outro tempo, marcadas pelo contexto semântico em que foram criadas, porém livres para criticar sua circunstância original de produção e consumo, e gerar novos sentidos em outros contextos.

\section{Referências}

ADORNO, T. O ensaio como forma. In: Notas de literatura I. São Paulo: Duas Cidades; Ed. 34, 2003.

ALMEIDA, R. Entre a chegada e a partida: reciclagens do cinema doméstico no filme-ensaio. Matrizes, v. 11, n. 2, p. 271-286, 31 ago. 2017.

ARTHUR, P. En busca de los archivos perdidos. Archivos de la Filmoteca, Valencia, España, feb, 2008.

ARTHUR, P. Essay questions: from Alain Resnais to Michael Moore. Film Comment, v. 39, n. 1, jan. 2003.

ELENA, A. Una estética del collage: documental, ensayo y vanguardia. In: VAQUERO, L. G.; LÓPEZ, S. G. (Org.). Piedra, papel y tijera: el collage en el cine documental. Madri: Ocho y medio libros de cine, 2009.

MACHADO, P.; BLANK, T. A outra vida das imagens: elaborando memórias de um Brasil invisível. Devires, Belo Horizonte, v. 12, n. 2, p. 68-93, jul.-dez. 2015.

ODIN, R. A questão do público: uma abordagem semiopragmática. In: RAMOS, F. (Org.). Teoria contemporânea do cinema, volume II: documentário e narratividade ficcional. São Paulo: Senac, 2005.

RASCAROLI, L. The personal camera: subjective cinema and the essay film. New York: Wallflower Press, 2009.

VAQUERO, L. G.; LÓPEZ, S. G. Introducción. In: VAQUERO, L. G.; LÓPEZ, S. G. (Org.). Piedra, papel y tijera: el collage en el cine documental. Madri: Ocho y Medio Libros de Cine, 2009.

WEES, W. C. Recycled images: the art and politics of found footage film. Anthology Film Archives, Nueva York, 1993. 
WEINRICHTER, A. Notas sobre collage y cine. In: VAQUERO, L. G.; LÓPEZ, S. G. (Org.). Piedra, papel y tijera: el collage en el cine documental. Madri: Ocho y Medio Libros de Cine, 2009.

ZRYD, M. Found Footage Film as Discursive Metahistory: Craig Baldwin's Tribulation 99. The Moving Image, Volume 3, Number 2, Fall, 2003.

\section{Sobre o autor}

Rafael de Almeida - Doutor em Multimeios pela Universidade Estadual de Campinas (Unicamp). Professor do curso de Cinema e Audiovisual da Universidade Estadual de Goiás (UEG).

Data de submissão: 09/1 1/2018

Data de aceite: 28/10/2019 